\title{
Selected Reference Books of 1973-74
}

\section{INTRODUCTION}

$\mathrm{T}$

HIS ARTICLE CONTINUES the semiannual series originally edited by Constance M. Winchell. Although it appears under a byline, the list is actually a project of the Reference Department of the Columbia University Libraries, and notes are signed with the initials of the individual staff members. ${ }^{1}$

Since the purpose of the list is to present a selection of recent scholarly and foreign works of interest to reference workers in university libraries, it does not pretend to be either well balanced or comprehensive. A brief roundup of new editions of standard works, continuations, and supplements is presented at the end of the column. Code numbers (such as AA71, 2BD89) have been used to refer to titles in the Guide to Reference Books and its supplements. ${ }^{2}$

\section{GuIDEs}

Ryder, Dorothy E., ed. Canadian Reference Sources; A Selective Guide. Ottawa, Canadian Library Assoc., 1973. 185p. \$10. 73-169642.

The result of a Canadian Library Association project, this selective, annotated bibliography designed "to provide librarians and students with a guide to Canadian reference material" covers "Canada in general, the ten provinces, the territories, and three cities."-Introd. Emphasis is on the country in general, the provinces receiving treatment in certain selected subjects, and

1. Diane Goon, Rita Keckeissen, Anita Lowry, Eileen McIlvaine, Nancy Schroeder, Doris Ann Sweet, Barbara Wendell.

2. Constance M. Winchell, Guide to Reference Books (8th ed.; Chicago: ALA, 1967); Supplement I (Chicago: ALA, 1968); Supplement II (Chicago: ALA, 1970); Supplement III (Chicago: ALA, 1972). the cities-Ottawa, Montreal, and Toronto -receiving merely token coverage. Publications through 1971 are included. Excluded are such specialized reference books as those dealing with individuals or particular laws.

The classified arrangement is presented in five broad categories: General Reference, History and Allied Subjects, Humanities, Science, and Social Science, with appropriate subdivisions. Full bibliographical information is given in each entry and the annotations as well as general introductory notes contain many useful references to related sources, not only by cross reference to included listings but also to works (properly) excluded. Four appendixes describe in detail Canadiana, Canadian Government Publications ...., Canadian Periodical Index, and Canadian Almanac and Directory. A fifty-page index of authors, titles, and selected subjects concludes the work. Supplements as well as subsequent editions are planned. This is a carefully edited guide, recommended for the large reference department in the U.S. and for Canadian libraries in general.-R.K.

\section{BIBLIOGRAPHY}

Index Translationum. Cumulative Index to English Translations, 1948-1968. Boston, G. K. Hall, 1973. 2v. \$295.

The first inaccuracy is in the title. This is an index to all monographic translations published in seven predominantly Englishspeaking countries-Australia, Canada, New Zealand, Republic of Eire, Republic of South Africa, United Kingdom, and the United States-as listed in volumes 1-21 (1948-1968) of the new series of Index Translationum (Guide AA91). Each listing includes author, title, translator, place of publication and publisher, pagination, price, and language of the original (publication date and original title are often included).

A cumulation, particularly one as highly 
priced as this, should be more than a cutand-paste job from earlier volumes, but this is not. Typographical errors abound; entries are erratic (variant forms have not been reconciled); and there are no cross references, which would have been particularly helpful. The translations are a mixed bag of literary works, monographs, doctoral dissertations, and conference proceedings. (Corporate and conference proceedings entries are particularly annoying: without cross references, how is the user to know that he should look under both "SSSR. Akademija nauk" and "Akademija nauk SSSR"?) Librarians and others have been waiting for a good cumulation of English-language translations, but at this price for this quality, many will be content to wait a little longer.-D.G.

Moreau, Brigitte. Inventaire chronologique des éditions parisiennes du XVI $I^{\mathrm{e}}$ siècle. Paris, Imprimerie Municipale, 1972

v.1- . (In progress) 73-327446.

Contents: v.1, 1501-1510. 36.00F.

Disturbed by the slowness with which the volumes of the monumental Imprimeurs et libraires parisiens $d u \mathrm{XVI}^{\mathrm{e}}$ siècle (Suppl. 1AA31, 3AA37) have been fated to appear, the compiler of this inventory has proposed to make at least the fundamental information concerning sixteenth-century Parisian printing and bookselling available to scholars within a more reasonable length of time. Modeled after the English and American short title catalogs, this chronological listing gives for each entry the author and brief title, printer, month and day of publication if they can be determined, format, locations in both European and American libraries, and citations to other more specialized bibliographies where fuller descriptions may be found. It is based, like Imprimeurs et libraires parisiens, on the manuscript notes left by Philippe Renouard at his death in 1934, but is not merely a transcription of them; Mlle. Moreau has verified each entry, added (in the first volume) more than a hundred titles not known to Renouard, and furnished precise dates for many previously undated items. The inclusion of author, title, printer, and geographical indexes in each volume (of which there are to be ten) greatly increases the usefulness of this bibliography. - N.S.

\section{ARCHIVES}

Iredale, David. Enjoying Archives: What They Are; Where to Find Them; How to Use Them. Newton Abbot, David \& Charles, [1973]. 264p. \&3.95. 73330885.

This basic introduction to "the great heritage of documents in England and Wales," and to some of the archives where they are stored, "aims to describe, in outline, the work of the county record office, the repair of manuscripts, and the method of reading old records."-Introd. Types of documents included are those "most commonly studied by the majority of historical researchers." The work's clarity, wealth of illustrative examples, careful definitions, and bibliographical detail-in short, its instructional character-should make it a vade mecum for the beginning researcher in English archival material.

Chapters cover research methods, national archives, family muniment rooms, cathedral, parish, company records, solicitor's office, newspapers, county record office, paleography, and handwriting in England. There are lists of repositories and national record societies, a helpful bibliography, and a subject index.-R.K.

\section{ENCYCLOPEDIAS}

Great Soviet Encyclopedia; A Translation of the Third Edition. [A. M. Prokhorov, ed. in chief]. N.Y.: Macmillan; London, Collier Macmillan, [1973]- . v.1- . (In progress) 73-10680.

Thirteen volumes (A-Kun) of the third edition of the Bolshaia Sovetskaia entsiklopediia (Suppl. 3AD10) have been received at this writing. The item under consideration here is the first volume of an English translation of that work. The translation is "unannotated and as true as possible to the content and meaning intended by the editors of the original edition in Russian," and as such is intended to convey the scope and point of view of the original, bringing to scholars and others an unaltered "primary source through which they can gain a richer knowledge and understanding of the contemporary Soviet Union."-Publisher's Foreword.

The work is being translated on a volume- 
for-volume basis (only those articles that can be considered simply dictionary or gazetteer entries are omitted) and articles are arranged within each translated volume according to the English form of the entry or transliterated form of personal and place names. Thus, while the preponderance of entries in v.1 begin with the letter "A", terms such as "Diamond," "Highway," and "Zulu War" are also found therein because the Russian form of these terms begins with the letter " $A$ ". Although this may make for a certain degree of awkwardness for use until the set is complete and the promised index published, it has the virtue of making the translated material available relatively soon after the publication of the parent work. Even so, the editors are taking care to make the information as current as possible by updating figures or factual information; when such updating is substantial, the translation is marked as "updated." Bibliographies appended to the Russian articles are carried over into the translated work, with Russian titles cited in transliteration and Western-language works in their original form. Each translated article is keyed to the text of the original by volume, page, and column. A full list of entries in the Russian volume is clearly marked to indicate those articles which have not been translated.-E.S.

The New Encyclopaedia Britannica. 15th ed. Chicago, Encyclopaedia Britannica, Inc., [1974] 30v. il. \$548. 73-81025.

Contents: Propaedia (Outline of Knowledge), 1v.; Micropaedia (Ready Reference and Index), 10v.; Macropaedia (Knowledge in Depth), 19v.

To review a major, multivolume work in a brief column of this kind often borders on the impertinent; to attempt an evaluation of "Britannica 3 " in so short a space is probably futile. One may try, however, to dispel some of the confusion regarding the tripartite structure of the new edition. Leaving aside, for the moment, the Propaedia, librarians familiar with Compton's Encyclopedia can easily relate the Micropaedia to the "Fact Index" of Compton's: i.e., the short factual articles of the Micropaedia stand in the same relationship to the longer, more comprehensive articles in the Macro- paedia as do the brief entries of the "Fact Index" to the related, full-length articles in Compton's. The ten-volume Micropaedia, then, is both the index to the Macropaedia and an independent ready reference source offering some 102,214 articles ranging from a few lines up to 750 words in length. The nineteen-volume Macropaedia comprises 4,207 "in depth" articles, none of which is less than 1,000 words in length. These are signed articles by a worldwide roster of authorities, and include selective, briefly annotated bibliographies.

Topics in the Micropaedia which are given fuller treatment under an identical heading in the Macropaedia are signalled by a volume and page reference immediately following the boldface entry; references to related articles in the Macropaedia are supplied at the end of many entries in the Micropaedia, and cross references are used freely throughout the ten-volume set. Users of the work would be well advised to begin always with the Micropaedia entries: salient facts and dates presented here may suffice, but more importantly, time will usually be saved since topical headings in the Macropaedia show considerable variation from those of the 14th edition and the direct-entry approach of many other encyclopedias. And, while biographies abound in the Micropaedia, relatively few figures have been accorded the fuller treatment of the Macropaedia.

The division between short and long articles is, in effect, a means of having the best of two worlds: a return, in the Macropaedia, to the longer, monographic articles of Britannica's 11th edition, while preserving in the Micropaedia the fragmented, specific-entry approach of the 14th edition. The Propaedia resulted from an attempt by the editors to construct a "workable and defensible" outline of human knowledge which would "set forth in some orderly way the major topical rubrics that must ultimately be dealt with in a general encyclopaedia." While many will view it as mere icing on the cake, it will also have its enthusiasts: its disciplinary overviews can be useful to the beginner in a given subject field, and its references to the Macropaedia can serve as a guide for independent study.

A few final observations: most articles are newly written (those in Macropaedia usu- 
ally by a scholar other than the contributor of the corresponding article in the 14th edition); maps are scattered throughout the set rather than collected in an atlas section; professional jargon has been eliminated as far as possible; and the language and style are such that "at least some portion of the article should be readable to the layman to whom, at a minimum, the significance and general bearings of the subject must be made comprehensible."-E.S.

\section{PeRIOdicals}

New Serial Titles; A Union List of Serials Commencing Publication after December 31, 1949. 1950-1970 Cumulative. Wash., D.C., Lib. of Congress; N.Y., Bowker, 1973. 4v. \$190. 53-60021.

This twenty-one-year cumulation of New Serial Titles (Guide AF99) represents considerably more than a mere cumulation of the information in the earlier volumes $(1950-60,1961-65,1966-69$, each in two volumes, plus the previously uncumulated 1970 quarterlies). The complete NST file has been converted to a computer data base, thousands of revisions have been incorporated, thousands of additional library locations supplied, and International Standard Serial Numbers (ISSN) added. The supplementary "Changes in Serials" section appears at the end of volume four. Although the cumulation was edited by the Bowker Company, utilizing that firm's computerproduced publication system, further NST quarterly and annual cumulations will continue to be published by Library of Congress.

Throughout the preparation of the work there was close collaboration between the Bowker Company and the Library of Congress Serial Record Division to assure that the product would be well up to the standard of NST. Librarians will do well, of course, to acquaint themselves with the introductory sections "Form of entry" and "Arrangement of entries," particularly the filing variations noted in the latter. The benefits of having this long, augmented cumulation need no comment.-E.S.

\section{Dissertations}

Comprehensive Dissertation Index, 18611972. Ann Arbor, Mich., Xerox Univer- sity Microfilms, 1973. 37v. \$2495. 7389046.

Contents: v.1-4, Chemistry; v.5, Mathematics and statistics; v.6-7, Astronomy and physics; v.8-10, Engineering; v.11-13, Biological sciences; v.14, Health and environmental sciences; v.15, Agriculture; v.16, Geography and geology; v.17, Social sciences; v.18-19, Psychology; v.20-24, Education; v.25-26, Business and economics; v.27, Law and political science; v.28, History; v.29-30, Language and literature; v.31, Communications and the arts; v.32, Philosophy and religion; v.33-37, Author index.

Few publications of recent years can have offered such distinct advantages as this one to the academic community in general. The time-consuming task of dissertation searching is drastically simplified and shortened through use of this computer-generated index (by key words and authors) which attempts to list all dissertations accepted at universities of the United States from the time of the first Yale dissertation in 1861 through 1972. (Numerous Canadian and other foreign universities are among the schools included, but no claim for completeness of listing is made for universities outside the United States.) In effect, $C D I$ supersedes the Library of Congress lists of American doctoral dissertations (Guide AI8), the Wilson lists (Guide AI9), and the various indexes to Dissertation $A b$ stracts (Guide AII1, 3AI2). It also includes some dissertations not found in those lists because the data base embraces many published and unpublished lists provided by the individual universities. (The editors note some conflicts and discrepancies resulting from reliance on these varied sources, but errors are to be corrected in forthcoming supplements, and incorrect entries will be deleted from the data base.) More than 417,000 dissertations are represented. Annual supplements are planned, and the possibility of regular cumulations is obvious.

Within each subject volume the listing is alphabetical by keyword, as in the Retrospective Index (Suppl. 3AI2). Full citations appear in both the author and subject listings: these include complete title, author's full name if known, date, university, pagination when available, citation to Dis- 


\section{6 / College d Research Libraries • July 1974}

sertation Abstracts or other printed list, and University Microfilms publication number for dissertations which are available on microfilm from that agency. Several improvements over the Retrospective Index (which, incidentally, has trade-in value toward purchase of $C D I$ ) are noted. In volumes covering a number of related disciplines such as "Social sciences," each of the subsections (Anthropology, Archeology, Folklore, etc.) begins on a new page and running heads designating the divisions are provided. Also, problems arising from names with "Jr.," "Sister," "Brother," etc., have been more satisfactorily handled.-E.S.

\section{LITERATURE}

The Romantic Movement Bibliography, 19361970; A Master Cumulation from ELH, Philological Quarterly and English Language Notes. Ed. and with a Pref. by A. C. Elkins, Jr. and L. J. Forstner. Ann Arbor, Pierian Pr., 1973. 7v. \$160.

In spite of its title, this is not a "cumulation" of the annual Romantic Movement Bibliography (Guide BD11; Suppl. 1BD4), but consists of reprints of the early listings, with the addition of a cumulative index. The user is still obliged to look in a number of different places-at least thirty-five for major figures covered each year-for articles on a single author or topic. The index, the most important feature of the set for libraries already owning the annual bibliographies, is disappointing. It is in three sections: (1) author/main entry/reviewer, subject index; (2) personal names, and subject index; (3) categories. The first, to be used for finding articles and reviews by modern critics, is adequate, though reference librarians will not like its use of idiosyncratic symbols to indicate multiple listings, reviews, and so on. The second, which lists entries on individual romantic authors, annoyingly fails to classify the sections on the major romantic writers, so that there are, for example, about 200 undifferentiated entries under Shelley. The category index is not a true subject index, but an alphabetical listing of the sections in each annual bibliography on the national literatures. Because the bibliographies are photographic reprints, no editing (notably where there are inconsistencies in the forms of names) has been done.
We should be grateful to the publisher for making this fine bibliography available again, but the form in which it has been reissued leaves much to be desired, especially at such a high price. The set exemplifies the kind of publishing that, in an age of paper, space, and budget shortages, cannot be encouraged.-N.S.

Herdeck, Donald E. African Authors; A Companion to Black African Writing. Washington, Black Orpheus Pr., 1973- . v.1- . il. Biennial. 73-172338.

Contents: v.1, 1300-1973. 605p. \$22.50.

The expanding field of African literature adds a new bio-bibliography in this guide to a major literature which to the present has been "little known and even less appreciated in the West."-Introd. Short sketches, alphabetically arranged, of 594 poets, novelists, critics, dramatists, and journalists of sub-Saharan Africa, Malagasy, and Mauritius constitute the major portion of the work. Biographies, designed to give a survey of a writer's life and work and a "reasonably complete summary of his achievements both in and outside of literature," include dates, education, professional training, position, honors, genres and languages, and complete citations to publications. A hundred pages of appendixes include essays and bibliographies on various aspects of African literature, lists of authors by genre, languages, sex, dates, and directories of publishers, journals, and bookshops. Biennial publication is planned with cumulations at longer intervals. $-R . K$.

Howard, Patsy C., comp. \& ed. Theses in English Literature 1894-1970. Ann Arbor, Pierian Pr., 1973. 387p. \$19.95.

- Theses in American Literature 1896-1971. Ann Arbor, Pierian Pr., 1973. 307 p. $\$ 19.95$.

These two long titles $(9,000$ entries for English literature, 7,000 for American) of unpublished baccalaureate and master's theses from more than two hundred universities, mainly in the United States and Canada, are intended to indicate fields of research heavily covered by students and those relatively unexplored, and to provide students with "convenient bibliographies on highly specialized topics." Each is said to be "the beginning of a series whose goal 
is to make a complete, easily accessible listing of theses in literature throughout the world."-Foreword. Only theses concerning writers are included in the volumes noted here; they are arranged alphabetically by author within an alphabetic arrangement of the author-subjects. Entry gives author's name, thesis title, degree, university, and year. There are author and "limited subject" indexes. Spot checking for one university's essays shows omissions, unexplained, since no statement of years covered for a given institution is made. The basis for inclusion is stated merely as "availability," without explanation as to whether availability for site use or interlibrary loan is meant, or whether the bibliographical description alone is "available." Only those libraries whose readers are specially interested in this type of graduate paper will need these compilations. - R.K.

\section{Fine Arts}

Literature on Byzantine Art, 1892-1967. Ed. by Jelisaveta S. Allen. [London], Mansell, for Dumbarton Oaks Center for Byzantine Studies, 1973- . v.1 (in 2v.)- . (Dumbarton Oaks Bibliographies Based on Byzantinische Zeitschrift. Ser.I, v.1- ) (In progress)

Contents: v.1, By location. Pt.1, Africa, Asia, Europe (A-Ireland); Pt.2, Europe (Italy-Z), Indices. $\& 24$.

The first volume of this new series is a topographically arranged cumulation of items pertinent to the history of art of specific places as drawn from the semiannual lists published 1892-1967 in III. Abteilung, "Bibliographische Notizien und Mitteilungen" of the Byzantinische Zeitschrift, primarily from the subdivision "Kunstgeschichte: Einzelne Orte." Volume 2 will cover the same source for the history of Byzantine art in general and according to individual art form (i.e., architecture, painting, sculpture, minor arts, illuminated manuscripts, etc.).

Arrangement is by geographic area, alphabetic first by continent, then by country, region, and site. Text of each entry is that of its original listing in $\mathrm{BZ}$, with full bibliographic details, BZ citations and, usually, critical annotation. Under a specific heading, journal articles, books, and contribu- tions to collections appear in chronological order. A "Key to periodicals and abbreviated titles" lists full information for journals cited and for selected collections. Author and place-name indexes are useful features. - R.K.

\section{Cinema}

Manchel, Frank. Film Study: A Resource Guide. Rutherford, N. J., Fairleigh Dickinson Univ. Pr., [1973]. 422p. \$18. 723262.

Addressing himself to teachers and to their questions about "whys and hows" of teaching about film, Manchel examines the cinema's claim to serious consideration as art and as social phenomenon. He presents a basic introduction to the elements of film and film language and to some profitable ways of approaching film in the classroom.

Although the author states that the book is not "an attempt to list definitively the various sources or materials connected with film study," the many citations in the text, footnotes, and selected bibliographies and filmographies provide a wide survey of important sources for film study and research -most of them annotated and evaluated in considerable detail. As a result, students and librarians, as well as teachers, can use the chapters on film literature, the genre film, stereotyping in film, themes in film, literature and film, early American film, and the history of film to locate relevant books, articles, and representative films. Seven indexes facilitate access to this wealth of information.-A.L.

\section{Social Sciences}

Goode, Stephen H. Population and the Population Explosion: A Bibliography for 1970. Troy, N.Y., Whitston, 1973. 361p. $\$ 17.72-87106$.

This work is a secondary bibliography, taking its listings of books and articles from a number of standard bibliographies, including Books in Print, Reader's Guide, P.A.I.S., Index Medicus, and Social Science and Humanities Index. It is the first volume of an annual series intended to cover each year's literature in the field defined simply as "population and the population explosion." There are two sections, one arranged by title and the other by subject, with an au- 
thor index at the end. Unfortunately the method of compilation facilitates errors, and a quick comparison with the primary bibliographies does turn up several, ranging from misspelled names to transposed numbers. Although the compiler describes it as a "near-complete world bibliography covering the book and periodical literature for 1970 " (Pref.), there appear to be no foreignlanguage entries. Furthermore, the extensive bibliographies in Population Index are not utilized, nor apparently are any national bibliographies outside the United States, nor any of the major international periodical indexes one might expect to be used in compiling a "near-complete world bibliography." A work as comprehensive as this one claims to be would be welcome in any social science reference collection, but its actual limitations make this one a disappointment.D.A.S.

Puerto Rican Research and Resource Center.

The Puerto Ricans: An Annotated Bibliography. Ed. by Paquita Vivo. N.Y., Bowker, 1973. 299p. \$14.95. 73-8825.

Compiled from a survey of major United States and Puerto Rican library catalogs, this ambitious undertaking brings together a selected, though relatively comprehensive, annotated list of materials designed to offer the English-speaking reader "a complete bibliographic overview of Puerto Ricans." Since it would be unsatisfactory for a bibliography on Puerto Rico to be comprised solely of English-language materials, many important items in Spanish are listed. Entries are grouped first by type of publication (i.e., books, government publications, journals) and then by subject, rather than the more traditional classed arrangement employed by Bravo in his Bibliografia Puertorriqueña (N.Y., 1972). A subject index and an author-title index compensate for this arrangement which may initially confuse the user. A useful feature is the list of U.S. and Puerto Rican publishers who are, according to the editor, able to supply many of the works listed. The editor recognizes that many works important to Puerto Rican studies are not immediately accessible in the United States and urges that a greater effort be made on the part of the U.S. distributors to obtain in-print works from Puerto Rico. This bibliography could be a useful selec- tion guide for librarians wishing to improve their Puerto Rican collections.-B.W.

\section{White, Carl M. Sources of Information in} the Social Sciences, a Guide to the Literature. $2 \mathrm{~d}$ ed. Chicago, American Library Association, 1973. 702p. \$25.00. 73-9825. The new edition of White's standard text reflects the growth in scope and diversity of the social sciences and their literature; it is larger than the 1964 edition by over 200 pages. The basic format remains the same. Chapters on the social sciences in general, and on specific fields, begin with a bibliographic essay by a subject specialist on the history and methodology of the field, with citations to basic monographs, and conclude with annotated lists of reference works; scholarly journals, monograph series, professional organizations, and occasionally films, maps, and photographs are also listed. A new chapter on geography has been added to the basic sections on social science literature, history, economics and business administration, sociology, anthropology, psychology, and education. The table of contents is much more detailed than that of the first edition, and the index now includes subjects as well as authors and titles.

Most of White's collaborators are new to this edition, and their bibliographic essays show shifts of emphasis. Much of the core monographic literature is classic works and has simply been updated, although some fields cite a greater number of post-1964 items than others. The reference sources have often been regrouped by form, type, or area for greater utility. Their annotations are exceptionally clear and incisive; the cutoff date seems to be early 1973 .

The content of the edition maintains the excellence of the previous one; the format far surpasses it. The organization and judicious use of spacing and type make the text highly legible and easy to consult. Librarians have eagerly awaited this new edition, and it is well worth the wait; it is, simply, an exceptional work.-D.G.

\section{HISTORY}

Hogg, Peter C. The African Slave Trade and Its Suppression: A Classified and Annotated Bibliography of Books, Pamphlets and Periodical Articles. London, 
Frank Cass, 1973. 409p. \&12.50. 7290130.

Here is a much needed bibliography of books, pamphlets, and periodical articles in Western languages discussing the African slave trade participated in not only by the English and Americans but also by France, Spain, Portugal, The Netherlands, Denmark, Brandenburg (for a short time) in West Africa, and by the Muslims in East Africa and the Sudan. Excluded are manuscripts and most government documents, and Mr. Hogg acknowledges an "unavoidable bias towards English language material."

The arrangement is by subject within two main sections: (1) Slave trade; (2) Abolition and suppression. Listing within each subject area is chronological by date of publication. An appendix brings coverage to 1972 , and a second appendix lists relevant master's essays and dissertations. The volume concludes with author, personal name, geographical name, and anonymous title indexes.-E.M.

Martin, Geoffrey Haward and McIntyre, Sylvia. A Bibliography of British and Irish Municipal History. Leicester, Leicester Univ. Pr., 1972- . v.1- . (In progress) 73-156398.

Contents: General works. 806p. $\& 12.50$.

This handsome bibliography is a joy to read and to use, from its graceful acknowledgments in the Preface and the well-written Introduction giving an overview of the study and interest in municipal history in Great Britain and Ireland, to the carefully prepared bibliography. A continuation of Gross' Bibliography of British Municipal History (Guide DC159), this work "comprises printed and published works on the history of municipal government and $\mathrm{mu}$ nicipal services in Great Britain and Ireland from the earliest times to the end of 1966." -p.liii.

In this first volume, books, documents, and journal articles are arranged in graded subdivisions under five general headings: Bibliographies and guides; General printed records (Texts and calendars); General history; The urban community; Municipal administration. These are followed by sections for materials concerned specifically with Wales, Scotland, and Ireland. The volume ends with an index of authors, publishers, sponsors, and place-names appearing in the Introduction as well as in the bibliography proper.-E.M.

\section{SCIENCE}

The Energy Index: A Select Guide to Energy Information Since 1970. N.Y., Environment Information Center, 1973- . Annual. ([v.1] 522p. \$50.) 73-89098.

Although it is not specifically stated to be such, this is essentially a "spin-off" from Environment Information Access (recently retitled Environment Abstracts). It derives from the same data base and is a reassembling, with cumulated indexes, of selected abstracts appearing in the 1971-73 Access volumes. (Further volumes of the Energy Index are to appear on an annual basis.) About half the abstracts are from the "Energy" section, but energy-related items from each of the other topical sections of Access have been included. There are author and subject indexes. In addition, there are lists of recent "energy books" and "energy films," and a section of statistical charts and tables gathered from a variety of sources. (The latter is the only substantial body of material not found in the publisher's other series.)

The index brings together a wide range of references from varied sources and, as with the materials abstracted in Environment Information Access, microform or hard copy of the full article or report may be ordered from the Environment Information Center. The series may prove useful in smaller or specialized collections, but the larger library already subscribing to Environment Information Access and its cumulated index, Environment Index, will not need this additional publication.-E.S.

\section{NEW EDITIONS AND SUPPLEMENTS}

A 1971 supplement to the Union Catalogue of Asian Publications edited by David Hall (London, Mansell, 1973. 704p. \&40) is the first of the annual series which will keep the original four-volume catalog up to date. As in the basic set, this supplement covers accessions reported by the cooperating British libraries during the period covered, not merely 1971 imprints. Users are urged to work backwards through the sup- 
plements to the main set, since errors are to be corrected in the supplements and earlier entries repeated to add new locations. The Bodleian Library is represented for the first time in the 1971 volume.

Although the content of the "Rev. ed., Jan. 1973" of the U.S. Government Printing Office Style Manual (Wash., D.C., 1973. 548 p. $\$ 4.70$ ) is not greatly changed from the 1967 edition (Suppl. 2AA34), there has been some slight rearrangement of sections, and new or substantially altered rules are marked with a star.

With the 15th edition, 1973-74, Ulrich's International Periodicals Directory (N.Y., Bowker, 1973. 2,706p. \$46.50) reverts to a single-volume format. Approximately 55,000 current titles are listed and, in addition to the usual directory information, the International Standard Serial Number is included for each entry. Suggested Dewey class numbers are also provided. David P. Woodworth's Guide to Current British Journals has appeared in a second edition (London, Library Assoc., 1973. \$37.50) in two volumes. Volume one is the list of journals with directory information; it retains the subject arrangement (by broad UDC classes) of the 1970 edition, and has been expanded to include some 4,700 titles. The second volume is called "Directory of Publishers," and supersedes Woodworth's Directory of British Journals (1971); it is an alphabetical listing of publishers with their addresses and journals published, plus an index by titles of the journals.

Newspapers on Microfilm (6th ed., 1967; Suppl. 2AG6) has a two-part successor: Newspapers in Microform: United States (Wash., D.C., Library of Congress, 1973. $1,056 \mathrm{p} . \$ 30)$ and Newspapers in Microform: Foreign Countries (Wash., D.C., Library of Congress, 1973. 269p. $\$ 10$.). Both volumes cover the period 1948-72 and include reports from libraries and commercial firms through summer 1972. The United States volume lists more than 34,000 titles; the foreign volume, more than 8,600 . Arrangement is the familiar geographical one, but title indexes are a new and useful feature. These hard-bound volumes are available separately, and each is a bargain.

Notable Names in American History
(Clifton, N.J., J. T. White Co., 1973. 725p.) constitutes a third edition of White's Conspectus of American Biography (2d ed., 1937; Guide AJ35). Expanded and updated to include information through 1972 in most cases, the work continues to be a useful compendium of chronological lists of officeholders of various kinds. Although an index of some 50,000 names has been added, references to biographies in the $\mathrm{Na}$ tional Cyclopaedia of American Biography are not supplied, and a number of lists have been dropped from this edition.

Cassell's Encyclopaedia of World Literature first appeared in two volumes in 1953, under the editorship of S. H. Steinberg (Guide BD19). In the new edition edited by J. Buchanan-Brown (London, Cassell, 1973. 3v. \&18), general articles (on literary genres, movements, terms, etc.) and brief histories of national literatures make up the whole of volume one; biographical articles, plus the occasional title entry, are now in a single alphabet (volumes two and three) rather than in the two period divisions (pre- and post-1914) of the earlier edition. Some new articles have been added, a few have been dropped, and bibliographies have been updated.

American Students: A Selected Bibliography on Student Activism and Related Topics by Philip G. Altbach and David H. Kelly (Lexington, Mass., Lexington Books, 1973. 537 p. $\$ 25)$ is a revised and greatly expanded version of Altbach's Student Politics and Higher Education in the United States (1968; Suppl. 2CB4). Books, periodical articles, and doctoral dissertations are again listed in classed arrangement; there is a detailed table of contents, but, unfortunately, no index. Richard C. Bain's Convention Decisions and Voting Records, originally published in 1960 (Guide CI67), has appeared in a second edition (Wash., Brookings Institution, 1973. 350p., plus tables. \$14.95) under the editorship of Bain and Judith H. Parris. Historical notes on the presidential nominating conventions and tables of voting records by states are provided through 1972.

A Guide to Historical Cartography, comp. by Walter W. Ristow and Clara E. LeGear, was first published by the Map Division of 
the Library of Congress in 1954 and issued in a revised edition in 1960 (Guide CK193). Ristow has now prepared a revised and greatly expanded version (nearly 400 entries) which is published under the title Guide to the History of Cartography; an Annotated List of References on the History of Maps and Mapmaking (Wash., D.C., Library of Congress, 1973. 96p. \$.75). The title change points up the fact that the bibliography is "concerned with the literature on the history and evolution of maps and mapmaking and not specifically with historical maps."-Pref.

The first volume, "Science and Technology" (London, Library Assoc., 1973. 615p. \$17.95) of the third edition of A. J. Walford's Guide to Reference Material again covers UDC classes five and six. It has "main entries for about 4,300 items, plus subsumed entries for roughly a further 700 " (Introd.), an increase of about 30 percent over the previous edition (1966).E.S. 